\title{
Plasma Interleukin-6 levels, glutathione peroxidase and isoprostane in obese women before and after weight loss. Association with cardiovascular risk factors
}

\author{
Maria Bougoulia, Athanassios Triantos, George Koliakos
}

Biochemistry Department, Aristotele University Medical School, Thessaloniki, Greece

\begin{abstract}
OBJECTIVE: To evaluate the levels of Interleukin-6 (IL-6), glutathione peroxidase and isoprostane in obese women and their association with markers of cardiovascular risk factors before and after weight loss. DESIGN: 36 healthy obese women of reproductive age (group A: age (mean \pm SD) $35.4 \pm 9.2$ years, Body Mass Index (BMI) $38.5 \pm 7 \mathrm{~kg} / \mathrm{m}^{2}$ ) and $30 \mathrm{healthy}$, normal weight women (group B: age mean \pm SD $34.9 \pm 7.4 y$., BMI $24 \pm 1.1 \mathrm{~kg} / \mathrm{m}^{2}$ ) were included in the study. Glucose tolerance was normal in all participating women. Il-6, glutathione peroxidase and isoprostane, C-Reactive Protein (CRP), insulin, fasting plasma glucose, HOMA-IR as well as the lipid profile were evaluated. Body weight, BMI, Waist to Hip ratio (W/H) ratio, Waist Circumference (WC), \%free fat mass and the \%fat mass were also measured. A hypocaloric diet was prescribed for the obese women and all participants were re-examined after six months. RESULTS: In obese women after weight loss, anthropometric obesity markers (BMI, W/H ratio), \%fat, lipid profile, insulin levels and inflamation indices such as IL-6 and CRP, the oxidative stress index isoprostane, as well as glutathione peroxidase were significantly ameliorated. The levels of serum glutathione peroxidase activity were negatively correlated with IL-6 levels and were significantly increased after weight reduction. In obese women there was an association between IL-6 levels and the values of \%fat, \%free fat mass, insulin and HOMA-IR before and after weight loss. CONCLUSIONS: Weight loss is related to reduction of oxidative stress and inflammation; this beneficial effect could possibly be translated into reduction of cardiovascular risk in obese individuals.
\end{abstract}

Key words: Body mass index, C-reactive protein, Glutathione peroxidase, Interleukin-6, Isoprostane, Obesity

\section{INTRODUCTION}

Obesity is the most common metabolic disorder

Address correspondence and requests for reprints to: Maria Bougoulia MD, 4 Imeras Str., Kalamaria, 55132, Thessaloniki, e-mail: mariabougoulia@hotmail.com

Received 11-04-06, Revised 28-05-06, Accepted 20-06-06 in developing countries and is characterized by a reduction in insulin sensitivity, both in animal models and in humans. ${ }^{1}$ Obesity has been associated with increased cardiovascular morbidity and mortality ${ }^{2-4}$ and is now considered a major independent risk factor for coronary heart disease. ${ }^{5}$ Furthermore, the 
degree of abdominal adiposity conveys an independent prediction of risk beyond body mass index (BMI) for cardiovascular pathology. ${ }^{4,6,7}$ Vascular endothelial dysfunction (VED) plays a pivotal role in the pathogenesis of atherosclerosis ${ }^{8}$ and enhances the risk for future cardiovascular events. The presence of VED has been demonstrated in overweight patients with insulin resistance ${ }^{9}$ and with visceral obesity. ${ }^{9,10}$ Therefore, VED may be an important link between obesity per se and heightened cardiovascular risk. However, the molecular mechanisms involved in obesity-related insulin resistance are not yet well understood. ${ }^{11}$ It has been clearly demonstrated that adipocytes are able to synthesize and secrete several cytokines, such as leptin, ${ }^{12}$ tumor necrosis factor (TNF $\alpha)^{13}$ and interleukin-6 (IL-6). ${ }^{14}$ Recently an attractive hypothesis has emerged proposing that cytokines produced by adipose tissue may be responsible for insulin resistance in obesity. ${ }^{2-5}$

IL-6 is a cytokine produced by different cell types, including immune and adipose tissue cells, and mediates inflammatory responses. Unlike other cytokines, IL-6 is distinct in that its major effects take place at sites distant from its origin. For this reason IL-6 has come to be known as "the endocrine cytokine". Circulating IL-6 levels constitute a significant proatherogenic cytokine.

The role of chronic inflammation in atherosclerosis has become well established during the past decade. Numerous epidemiological studies have demonstrated an association of CRP levels with increased risk of myocardial infarction (MI), stroke, sudden cardiovascular death and peripheral vascular disease. ${ }^{15}$ Furthermore, the synthesis of CRP by the liver has been shown to be largely regulated by IL-6. ${ }^{15,16}$

Recently reported population-based data from the Women's Health Study demonstrated that a single nonfasting measurement of $\mathrm{CRP}^{1}$ is a stronger predictor of future cardiovascular events than LDL cholesterol, ${ }^{2}$ identifies at-risk individuals with low LDL cholesterol levels and ${ }^{3}$ adds prognostic information to the currently used Framingham risk algorithm. ${ }^{17}$

It has recently been reported that $\mathrm{F} 2$ isoprostanes are the most reliable indicators of oxidative stress, although their role in pathophysiologic processes is unknown. ${ }^{18}$ The measurement of F2 isoprostanes may represent an important development in the assessment of free radical generation and oxidative stress in vivo. Glutathione peroxidase is an antioxidant enzyme that reduces hydrogen peroxide and lipid peroxides. In the reduced state, glutathione (GSH) is an indirect indicator of oxidative stress. GSH may also be an important antiatherogenic agent, is present in human plasma and intracellularly, has antioxidant properties by inhibiting free radical formation and generally functions as a redox buffer. ${ }^{19}$

The above data underline the need for further clarification of the metabolic and endocrine function of adipose tissue in obese subjects. We thus sought to investigate the relationships between cytokines, proinflammatory products and oxidative stress, as well as their relation to cardiovascular risk factor in obese women and their possible modification by weight reduction.

\section{METHODS}

Thirty-six obese women of reproductive age (group A: mean \pm SD age 35.4 $\pm 9.2 y r$, BMI 38.5 \pm 7 $\mathrm{kg} / \mathrm{m}^{2}$ ) and 30 normal weight women (group B: mean \pm SD age $34.9 \pm 7.4 \mathrm{yr}, \mathrm{BMI} 24 \pm 1.1 \mathrm{~kg} / \mathrm{m}^{2}$ ) were studied. All participants were informed about the objectives of the study and volunteered to participate. All individuals included in the study (groups A and B) had two menses in the 3 months before the testing and displayed a normal response to oral glucose tolerance test (OGTT).

Additional exclusion criteria included diabetes mellitus, hormone replacement therapy, pregnancy, lactation, psychiatric or neurological disorders, alcohol abuse, a history or the presence of malignancy, coronary heart disease and cerebrovascular disease. Continuing use of antihypertensive medication was permitted provided that the dose had been stable for at least 3 months before entry into the study.

None of the subjects was taking any medication known to influence lipid metabolism. Apart from obesity, all obese subjects were in good health and had maintained stable body weight for at least 12 
months prior to entering the study. None was engaged in any type of exercise program or was excessively sedentary. All participants underwent physical examination, measurement of fat mass and complete biochemical investigations.

Anthropometric parameters such as Body Weight (BW), height, BMI, Waist Circumference (WC), Waist to Hip ratio $(\mathrm{W} / \mathrm{H})$ and \%Body fat as well \%Free fat mass (FFM) were also evaluated.

Weight in $\mathrm{Kg}$ was determined using a standard beam-balance scale and with the subjects barefoot and wearing light indoor clothing. Height in centimeters was measured using a meter rule built into the scale. BMI was calculated by dividing weight in $\mathrm{Kg}$ by height in meters squared. Obesity was defined as a BMI value greater than $30 \mathrm{~kg} / \mathrm{m}^{2}$. Waist circumference was measured with a flexible measuring tape, taking as a reference the midway line between the costal inferior border and the iliac crest. Body fat mass was evaluated by a bioelectric impedance analysis device (Bodystat Ltd, Isle of Man, Bodystat 1500).

Morning fasting blood samples were obtained both at entrance to the study and after the treatment period. All biochemical measurements were performed on frozen plasma samples obtained by centrifugation of the freshly drawn blood $(3000 \mathrm{Xg}$ for $20 \mathrm{~min}$ at $4^{\circ} \mathrm{C}$ ) and subsequent storage at $-70^{\circ} \mathrm{C}$.

The tests included measurement of insulin, IL6 , CRP, glutathione peroxidase activity and isoprostane.

Bio-electrical impedance analysis (BIA), a method that measures the impedance or opposition to the flow of an electric current through the body fluids, was evaluated as follows: a small constant current, typically $400 \mathrm{uA}$ at a fixed frequency, usually $50 \mathrm{kHz}$, passed between electrodes spanning the body and the voltage drop between electrodes provided a measure of impedance.

Prediction equations, previously generated by correlating impedance measures against an independent estimate of TBW, were used subsequently to convert measured impedance to a corresponding estimate of TBW. Lean body mass was then calculated from this estimate using an assumed hydra- tion fraction for lean tissue. Fat mass was calculated as the difference between body weight and lean body mass. ${ }^{20,21}$

OGTT was performed as follows: all subjects ingested a 75g glucose solution after an overnight fast. Serum samples were collected before and 30, 60, 90 and $120 \mathrm{~min}$ after the glucose load. The criteria developed by the World Health Organization Expert Committee on Diabetes Mellitus were used to determine whether a subject was not diabetic (2-h glucose concentration $<140 \mathrm{mg} / \mathrm{dl}) .{ }^{22}$ Insulin resistance was calculated based on homeostasis model assessment (HOMA-IR) index. The homeostasis model assessment (HOMA) has been suggested as a method to assess IR and is calculated using the formula HOMA-IR = fasting insulin (units $/ \mathrm{ml}$ ) $\times$ fasting glucose $(\mathrm{mmol} / \mathrm{l}) / 22.5){ }^{23}$

Obese women were subscribed a hypocaloric diet according to the following calculation: $[18-40 \mathrm{y}=$ $0.0621 \mathrm{x}$ weight in $\mathrm{Kg}+2.0357=-\mathrm{mJ} /$ day $\mathrm{x} 240=-$ $-\mathrm{Kcal} /$ day, adjusting with daily activities: $--\mathrm{Kcal} /$ day $\mathrm{x}-$ coefficient of daily activities $=--\mathrm{Kcal} /$ day, in order to have hypocaloric diet $--\mathrm{Kcal} /$ day$600 \mathrm{Kcal} /$ day]. ${ }^{24}$ The energy distribution of this diet was $50 \%$ carbohydrates, $30 \%$ fat and $20 \%$ protein and the duration of dietary intervention was 6 months.

Serum glucose levels were measured using the chromatographic method (bioanalyzer Wako Chemicals $\mathrm{GmbH}$ ), cholesterol, triglyceride and HDL were measured by standardized laboratory methods and LDL-cholesterol level was calculated with the Friedewald formula. Insulin by immunoradiometric assay using a Sorin-Biomedica Kit (Saluggia, Italy). The lower limits of detection for insulin was 0.3 $\mu \mathrm{IU} / \mathrm{ml}$ while inter-assay and intra-assay coefficients of variation (CV) were 6.9 and $6.4 \%$, respectively. Normal range for our laboratory is $2-25 \mu \mathrm{IU} / \mathrm{ml}$.

IL-6 levels were determined by enzyme-linked immunosorbent assay (Quantikine High Sensitivity IL-6; R\&D Systems, Oxford, UK). The sensitivity of this assay was $0.70 \mathrm{pg} / \mathrm{mL}$ IL-6. Plasma levels of peroxidase of glutathione were determined by use of an enzymatic assay (BIOXYTECH of company OxisResearch, Inc Portland, USA) that allows a recovery of GSH $>90 \%$ and has no appreciable inter- 
ference with other thiols present in the plasma or in the reactive mixture; meanwhile, levels of isoprostane (8-iso-PGF2) were determined using the enzymatic method elisa by Assay Designs' Correlate-EIA $^{\mathrm{TM}}$ Direct 8-iso-Prostaglandin F2kit.

\section{Statistical methods}

For statistical analysis the statistical package SPSS 11.5. (SPSS, Chicago, IL, USA) was used. Results are expressed as mean \pm standard deviation (SD). Normality was assessed by the Kolmogorov-Smirnov test. The unpaired Student-t test was used for comparisons between normal and obese individuals. The paired Student-t test was used for comparisons between baseline and 6 months of treatment in obese women. For correlations the Pearson correlation coefficient was used. $P$-values $<0.05$ were considered statistically significant.

\section{RESULTS}

The results of this study showed significant differences between group A and group B with regard to the anthropometric parameters \%body fat and $\%$ free fat mass $(\mathrm{p}<0.001)$ but not the age (Table $1)$.

The mean values of cholesterol, triglycerides and LDL cholesterol were not significantly different between the obese and the controls, whereas HDL levels were significantly lower in the obese group than in the normal weight group (Table 2).

The mean values of CRP, insulin, IL-6, HOMAIR and isoprostane were significantly higher in the obese women as compared to the normal weight con-

Table 1. Anthropometric indices of obese women at entrance to the study (group A) and of normal weight women (group B) (mean \pm SD)

\begin{tabular}{lccc}
\hline & $\begin{array}{c}\text { Group A } \\
(\mathbf{n = 3 6})\end{array}$ & $\begin{array}{c}\text { Group B } \\
(\mathbf{n = 3 0})\end{array}$ & P value \\
\hline Age $(\mathrm{yr})$ & $35.4 \pm 9.2$ & $34.9 \pm 7.4$ & $<0.456$ \\
Weight $(\mathrm{kg})$ & $102.1 \pm 18.7$ & $60.2 \pm 5.3$ & $<0.001$ \\
Body mass index $\left(\mathrm{kg} / \mathrm{m}^{2}\right)$ & $38.5 \pm 7$ & $24 \pm 1.1$ & $<0.001$ \\
Waist hip ratio & $0.9 \pm 0.06$ & $0.7 \pm 0.04$ & $<0.01$ \\
Waist circumference $(\mathrm{cm})$ & $108.5 \pm 10.6$ & $74.5 \pm 15$ & $<0.001$ \\
\%Fat mass & $42.5 \pm 8.1$ & $26.5 \pm 3.9$ & $<0.001$ \\
\%Free fat mass & $57.9 \pm 8.2$ & $73.4 \pm 3.8$ & $<0.001$ \\
\hline
\end{tabular}

Table 2. Biochemical and hormonal values of obese women at entrance to the study (group A) and of normal women (group B) $($ mean $\pm \mathrm{SD})$

\begin{tabular}{lccc}
\hline & $\begin{array}{c}\text { Group A } \\
\text { Obese Women } \\
(\mathbf{n = 3 6})\end{array}$ & $\begin{array}{c}\text { Group B } \\
\text { Controls } \\
(\mathbf{n = 3 0})\end{array}$ & P value \\
\hline Insulin(IU/ml) & $41 \pm 30$ & $11,7 \pm 6,6$ & $<0.001$ \\
Cholesterol (mg/dl) & $209.5 \pm 43.7$ & $185.7 \pm 38.5$ & $<0.356$ \\
Triglycerides (mg/dl) & $141.5 \pm 42.9$ & $134.3 \pm 42$ & $<0.667$ \\
HDL (mg/dl) & $42.1 \pm 10.3$ & $47.5 \pm 9.4$ & $<0.05$ \\
LDL (mg/dl) & $131.2 \pm 43.9$ & $118.5 \pm 37.9$ & $<0.335$ \\
IL-6(pg/ml) & $83 \pm 17$ & $2.34 \pm 1.7$ & $<0.001$ \\
CRP(mg/l) & $8.5 \pm 3.9$ & $2.5 \pm 1.1$ & $<0.001$ \\
HOMA-IR & $10.1 \pm 8.2$ & $2.5 \pm 1.6$ & $<0.001$ \\
Isoprostane (pg/ml) & $5166.4 \pm 1787.2$ & $502 \pm 202.8$ & $<0.001$ \\
Glutathione & $22.3 \pm 9.5$ & $67.5 \pm 21.3$ & $<0.001$ \\
peroxidase (ng/ml) & & & \\
\hline
\end{tabular}

For SI units multiply for insulin by 7.175 , for cholesterol, LDL and HDL by 0.02586 , for triglycerides by 0.01536 .

trols $(\mathrm{p}<0.001)$ (Table 2).

Glutathione peroxidase was significantly lower in the obese women than in the controls $(\mathrm{p}<0.001)$ (Table 2).

The biochemical and hormonal values as well as anthropometric indices in the obese women before and after weight reduction are presented in Table 3.

The mean weight, BMI, W/H ratio, waist circumference, $\%$, body fat, cholesterol, triglycerides, CRP, insulin, HOMA-IR, interleukin-6 and isoprostane were significantly reduced after weight loss $(p<0.001)$, whereas glutathione peroxidase was significantly increased after weight reduction ( $p$ $<0.001)$.

The data presented in Table 4 indicate a positive correlation of BMI (group A) with $\mathrm{W} / \mathrm{H}$ ratio $(\mathrm{r}=0.652, \mathrm{p}<0.001)$, insulin $(\mathrm{r}=0.501, \mathrm{p}<0.002)$, $\%$ fat $(\mathrm{r}=0.870, \mathrm{p}<0.001)$, HOMA-IR $(\mathrm{r}=0.545$, $\mathrm{p}<0.001)$, and glutathione $(\mathrm{r}=0.331, \mathrm{p}<0.049)$, whereas it was negatively correlated with \%free fat mass $(r=-0.789, p<0.001)$ before weight reduction.

Table 5 shows a positive correlation of $\mathrm{W} / \mathrm{H}$ ratio in group A with BMI ( $\mathrm{r}=0.652, \mathrm{p}=<0.001)$, \% fat $(r=0.627, p<0.001)$ and a negative one of $\mathrm{W} / \mathrm{H}$ ra- 
Table 3. Anthropometric indices, biochemical and hormonal values in obese women before and after weight reduction $($ mean \pm SD)

\begin{tabular}{|c|c|c|c|}
\hline & Before & After & P value \\
\hline Weight (kg) & $102.1 \pm 18.7$ & $82.5 \pm 14.8$ & $<0.001$ \\
\hline Body mass index $\left(\mathrm{kg} / \mathrm{m}^{2}\right)$ & $38.5 \pm 7$ & $30.9 \pm 5.7$ & $<0.001$ \\
\hline Waist hip ratio & $0.9 \pm 0.06$ & 0.8 & $<0.001$ \\
\hline Waist circumference $(\mathrm{cm})$ & $108.5 \pm 10.6$ & $94.1 \pm 9.4$ & $<0.028$ \\
\hline$\%$ Fat mass & $42.5 \pm 8.1$ & $34.7 \pm 7.3$ & $<0.001$ \\
\hline$\%$ Free fat mass & $57.9 \pm 8.2$ & $64.6 \pm 6.9$ & $<0.001$ \\
\hline Insulin (IU/ml) & $41 \pm 30$ & $26.9 \pm 18.3$ & $<0.001$ \\
\hline Cholesterol (mg/dl) & $209.5 \pm 43.7$ & $169.7 \pm 27.2$ & $<0.001$ \\
\hline Triglycerides (mg/dl) & $141.5 \pm 42.9$ & $125 \pm 40$ & $<0.002$ \\
\hline $\mathrm{HDL}(\mathrm{mg} / \mathrm{dl})$ & $42.1 \pm 10.3$ & $33.9 \pm 8.2$ & $<0.001$ \\
\hline $\mathrm{LDL}(\mathrm{mg} / \mathrm{dl})$ & $131.2 \pm 43.9$ & $116.9 \pm 28.5$ & $<0.688$ \\
\hline IL-6 (pg/ml) & $83 \pm 17$ & $11.7 \pm 3.1$ & $<0.001$ \\
\hline CRP (mg/l) & $8.5 \pm 3.9$ & $6.6 \pm 3.3$ & $<0.007$ \\
\hline HOMA-IR & $10.1 \pm 8.2$ & $6.5 \pm 4.6$ & $<0.001$ \\
\hline Isoprostane (pg/ml) & $5166.4 \pm 1787.2$ & $1472.2 \pm 506.4$ & $<0.001$ \\
\hline Glutathione peroxidase (ng/ml) & $22.3 \pm 9.5$ & $48.9 \pm 14.1$ & $<0.001$ \\
\hline
\end{tabular}

For SI units multiply for insulin by 7.175 , for cholesterol, LDL and HDL by 0.02586 , for triglycerides by 0.01536 .

Table 4. Correlations of BMI in obese women (group A) with W/H ratio, WC, $\%$ fat, $\%$ free fat mass, cholesterol, triglycerides, CRP, HOMAIR, insulin and glutathione before weight reduction

\begin{tabular}{lccccccccccc}
\hline & W/H & WC & \%FAT & \%FFM & CHOL & TRG & INS & HOMA & CRP & GLUT \\
\hline r-pearson & 0.652 & 0.533 & 0.870 & -0.789 & 0.391 & 0.366 & 0.501 & 0.545 & 0.452 & 0.331 \\
p & $<0.001$ & $<0.001$ & $<0.001$ & $<0.001$ & $<0.020$ & $<0.031$ & $<0.002$ & $<0.001$ & $<0.001$ & $<0.049$ \\
\hline
\end{tabular}

BMI: Body mass index; W/H: waist to hip ratio; WC: waist circumference; FFM: free fat mass; HOMA-IR: homeostasis model assessment index; CRP: C-reactive protein; ins: insulin; GLUT: glutathione peroxidase activity

tio with \%FFM ( $\mathrm{r}=-0.561, \mathrm{p}<0.001)$ and LDL $(\mathrm{r}=$ $-0.45, \mathrm{p}<0.039)$ before weight loss.

Insulin levels of the obese women were positively correlated with BMI $(\mathrm{r}=0.381, \mathrm{p}<0.022)$ and HOMA-IR $(r=0.973, p<0.001)$ after weight loss as shown in Table 6.

IL-6 levels of the obese women (group A) correlated positively with \%body fat $(r=0.275, p<0.020)$,

Table 5. Correlations of $\mathrm{W} / \mathrm{H}$ ratio in group A with BMI, \%fat, \% free fat mass, LDL before weight reduction

\begin{tabular}{lcccc}
\hline & BMI & \%FAT & \%FFM & LDL \\
\hline r-pearson & 0.652 & 0.627 & -0.561 & -0.45 \\
p-value & $<0.001$ & $<0.001$ & $<0.001$ & $<0.039$ \\
\hline
\end{tabular}

HOMA-IR $(\mathrm{r}=0.484, \mathrm{p}<0.003)$ insulin $(\mathrm{r}=0.470$, $\mathrm{p}<0.004)$ and negatively with \%FFM $(\mathrm{r}=-0.279$, $\mathrm{p}<0.019)$ and glutathione $(\mathrm{r}=-0.340, \mathrm{p}<0.046)$ after weight loss (Table 7, Figure 1)

$\%$ Body fat correlated positively with BMI $(\mathrm{r}=$ $0.709, \mathrm{p}<0.001), \mathrm{WC}(\mathrm{r}=0.400, \mathrm{p}<0.001)$, insulin $(\mathrm{r}=0.388, \mathrm{p}<0.001), \mathrm{CRP}(\mathrm{r}=0.382, \mathrm{p}<0.001)$, IL-6 $(\mathrm{r}=0.275, \mathrm{p}<0.020)$ and negatively with $\% \mathrm{FFM}(\mathrm{r}=$ $-0.875, \mathrm{p}<0.001)$ and HDL $(\mathrm{r}=-0.262, \mathrm{p}<0.027)$ af-

Table 6. Correlations of insulin levels in group A with BMI, and HOMA-IR after weight reduction

\begin{tabular}{lcc}
\hline & BMI & HOMA-IR \\
\hline r-pearson & 0.381 & 0.973 \\
p-value & $<0.022$ & $<0.001$ \\
\hline
\end{tabular}


Table 7. Correlations of IL-6 levels in group A with HOMA-IR, \%fat, \%FFM, GLUT and insulin values after weight reduction

\begin{tabular}{lccccc}
\hline & HOMA-IR & INS & \%FAT & \%FFM & GLUT \\
\hline r-pearson & 0.484 & 0.470 & 0.275 & $-0,279$ & $-0,340$ \\
p-value & $<0.003$ & $<0.004$ & $<0.020$ & $<0,019$ & $<0,046$ \\
\hline
\end{tabular}

GLUT: glutathione peroxidase activity

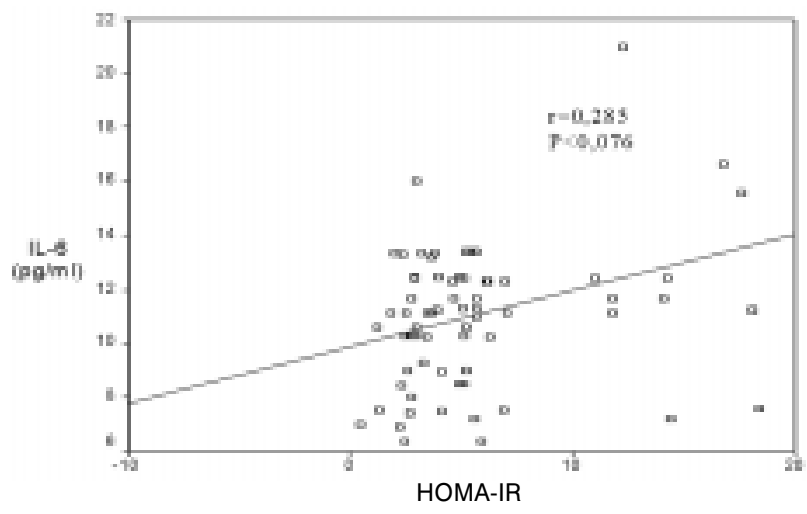

Figure 1. Correlation of IL-6 with HOMA-IR after weight reduction in group $\mathrm{A}$.

ter weight loss (Table 8).

\section{DISCUSSION}

Obesity is associated with an increased risk of developing cardiovascular diseases. ${ }^{2,4}$ The metabolic consequences of obesity can promote the process of atherosclerosis influencing endothelial function as well as the mechanisms of oxidative stress. ${ }^{9,10}$ In our study the levels of adipose tissue related cytokines, oxidative and antioxidative substances were evaluated in obese women (group A) before and after weight reduction and in normal weight women (group B).

The obese women also presented visceral obesity as indicated by the values of $\mathrm{WC}$ and $\mathrm{W} / \mathrm{H}$ ratio $(108.9 \mathrm{~cm}$ and $0.9 \mathrm{~cm}$, respectively) (Table 1$)$. The women in group A had lower HDL values than those in group B with no difference in total cholesterol,
LDL-cholesterol or triglycerides.

BMI values in group A correlated positively with $\mathrm{W} / \mathrm{H}$ ratio, WC, \%body fat, insulin, HOMA-IR, cholesterol, triglycerides, CRP and glutathione peroxidase activity and negatively with \% free fat mass (Table 4). \% Body fat was positively correlated with BMI, WC, plasma insulin concentration, CRP and IL-6. The latter correlation is a predictable relationship between the total body fat and risk factors, which are believed to be responsible for the chronic endothelial inflammation. ${ }^{15-17}$ Fernandez-Real J.M. et al reported that the omental adipose tissue produces 3-fold higher levels of IL-6 than subcutaneous adipose tissue and this is the major mediator of inflammation, which induces the hepatic synthesis of CRP. ${ }^{25}$ The findings of Lemieux et $\mathrm{al}^{26}$ and Forouhi et $\mathrm{al}^{27} 1$, suggested that fat distribution correlated with CPR levels as well as with other markers, such as BMI and WC. Although these studies show that there is a correlation between the low levels of inflammatory markers and the low body and splachnic adiposse tissue, the influence of weight reduction in the obese on the levels of these markers has not previously been studied. Previous studies have also suggested that CRP can predict future cardiovascular events independently of other more traditional cardiovascular risk factors, such as plasma lipid levels. ${ }^{28-31}$ One possible link between subclinical inflammation and cardiovascular disease (CVD) may be insulin resistance. In the study of Festa et al, 1008 nondiabetic individuals were evaluated. In this study CRP levels were significantly correlated with cardiovascular risk factors. ${ }^{33}$ Increased fasting levels of insulin and HOMA-IR seem to be mainly

Table 8. Correlations of \%body fat in group A with BMI, WC, \%FFM, insulin, CRP, HDL and IL-6 after weight reduction

\begin{tabular}{lcccccccc}
\hline & BMI & WC & \%FFM & HDL & INS & CRP & IL-6 \\
\hline r-pearson & 0.709 & 0.400 & -0.875 & -0.262 & 0.388 & 0.382 & 0.275 \\
P-value & $<0.001$ & $<0.01$ & $<0.001$ & $<0.027$ & $<0.001$ & $<0.001$ & $<0.020$ \\
\hline
\end{tabular}


related with the levels of the important proinflammatory cytokine IL-6. ${ }^{34,36}$ This is in accordance with our results of increased levels of insulin, HOMAIR and IL-6 in the obese group (A). Furthermore, fasting hyperinsulinemia is related with the production of free radicals. ${ }^{37-39}$ The data of the present study indicate that serum CRP as well as IL-6 circulating levels decreased during weight loss, supporting the beneficial effect of weight reduction on cardiovascular risk factor. Our data are in accordance with other studies, indicating a possible link between adipose tissue and secretion of IL- $6 .{ }^{1}$ In our study IL-6 levels as well as isoprostane were significantly higher and glutathione peroxidase significantly lower in obese subjects compared to controls (group A) (Table 2). Furthermore, IL-6 levels positively correlated with isoprostane and negatively with glutathione peroxidase in the obese, a finding which has not been previously described (Table 7). After weight reduction the levels of insulin, CRP, IL-6 and isoprostane significantly decreased, whereas glutathione peroxidase significantly increased.

These results are in accordance with the beneficial effect of weight loss considering that increased glutathione peroxidase activity protects tissues from oxidative stress injury (Table 3). Accordingly, it is suggested that the improvement of inflammation factors results in a decrease of cellular destruction and protects from CVD. In other words, low values of glutathione peroxidase along with higher levels of isoprostane in obese women indicate defective protection mechanisms against atherosclerosis and oxidative stress. In obese women despite the improvement in BMI values (from 38.5 to $30.93 \mathrm{~kg} / \mathrm{m}^{2}$ $\mathrm{p}<0.001$ ), following therapeutic interventions, the levels of IL-6, insulin and antioxidative substances did not reach levels similar to the controls. It can be speculated that normalization of these parameters requires either greater BMI reduction and/or a longer period of dietary intervention. However, the approximately $20 \%$ decrease in body weight and the reduction in adiposity, as was reflected in the decreased ratio of fat to free-fat mass in group A, was associated with an improvement in all adverse parameters measured in this study.

It seems that adipose tissue produces peptides and cytokines which alter not only the hormonal milieu but also certain biochemical parameters and oxidative stress. The results of this study demonstrate that the elevated circulating IL-6, isoprostane and CRP levels and the decreased levels of glutathione peroxidase found in obese women correlated significantly with a number of cardiovascular risks factors and were ameliorated by weight reduction.

In conclusion, the data of the present study indicate that individuals with high BMI and central obesity have increased levels of markers associated with insulin resistance, vascular inflammation, oxidative stress and atherosclerosis. Weight reduction can improve all these parameters and, therefore, a possible reduction of the metabolic and cardiovascular morbidity of obesity is expected.

\section{REFERENCES}

1. Bastard JP, Jardel C, Bruckert E, et al, 2000 Elevated levels of interleukin 6 are reduced in serum and subcutaneous adipose tissue of obese women after weight loss. J Clin Endocrinol Metab 85: 3338-3342.

2. Brook RD, Bard RL, Rubenfire M, Ridker Pm, Rajagopalan S, 2001 Usefulness of visceral obesity (waist/ hip ratio) in predicting vascular endothelial function in healthy overweight adults. Am J Cardiol 88: 12641269.

3. Stevens J, Cai J, Pamuk ER, et al, 1998 The effect of age on the association between body mass index and mortality. N Engl J Med 338: 1-8.

4. Overweight, obesity, and health risk. National Task Force on the Prevention and Treatment of Obesity 2000. Arch Intern Med 160: 898-904.

5. Eckel RH, Krauss RM, 1998 American Heart Association call to action: obesity as a major risk factor for coronary heart disease. AHA Nutrition Committee. Circulation 97: 2099-2100.

6. Terry RB, Page WF, Haskell WL, 1992 Waist-hip ratio, body mass index and premature cardiovascular disease mortality in US Army veterans during a twenty-three year follow up study. Int J Obes 16: 417-423.

7. Walton C, Lees B, Crook D, et al, 1995 Body fat distribution, rather than overall adiposity, influences serum lipids and lipoproteins in healthy men independently of age. Am J Med 99: 459-464.

8. Suwaidi JA, Hamasaki S, Higano ST, et al, 2000 Longterm follow-up of patients with mild coronary artery disease and endothelial dysfunction. Circulation 101: 948-954.

9. Steinberg HO, Chaker H, Leaming R, et al, 1996 Obesity/insulin resistance is associated with endothelial 
dysfunction: implications for the syndrome of insulin resistance. J Clin Invest 97: 2601-2610.

10. Arcaro G, Zamboni M, Rossi L, et al, 1999 Body fat distribution predicts the degree of endothelial dysfunction in uncomplicated obesity. Int J Obes 23: 936-942.

11. Mohamed-Ali V, Pinkney JH, Coppack SW, 1998 Adipose tissue as an endocrine and paracrine organ. Int J Obes 22: 1145-1158.

12. Caro JF, Sinha MK, Kolaczybski JW, et al, 1996 Leptin: the tale of an obesity gene. Diabetes 45: 1455-1462.

13. Hotamisligil GS, Shargill NS, Spiegelman BM, 1997 Adipose expression of tumor necrosis factor-a: direct role in obesity-linked insulin resistance. Science 259: 87-91.

14. Mohamed-Ali V, Goodrick S, Rawesh A, et al, 1997 Subcutaneous adipose tissue releases interleukin-6, but not tumor necrosis factor-a, in vivo. J Clin Endocrinol Metab 82: 4196-4200.

15. Ridker PM, 2003 Clinical application of C-reactive protein for cardiovascular disease detection and prevention. Circulation 107: 363-369.

16. Heinrich PC, Castell JV, Andus T, 1990 Interleukin-6 and the acute phase response. Biochem J 265: 621636.

17. Ridker PM, Rifai N, Rose L, et al, 2002 Comparison of C-reactive protein and low-density lipoprotein cholesterol levels in the prediction of first cardiovascular events. N Engl J Med 347: 1557-1565.

18. Sampson MJ, Hughes DA, Gopaul N, et al, 2002 Plasma F2 isoprostanes: direct evidence of increased free radical damage during acute hyperglycemia in type 2 diabetes. Diabetes Care 25: 537-541.

19. Hwang C, Sinskey AJ, Lodish HF, 1992 Oxidized redox state of glutathione in the endoplasmic reticulum. Science 257: 1496-1502.

20. Marra M, 2003 The prediction of basal metabolic rate in young adult, severely obese patients using singlefrequency bioimpedance analysis. Acta Diabetol 40: Suppl 1: 139-141.

21. Steiner MC, 2002 Bedside methods versus dual energy X-ray absorptiometry for body composition measurement in COPD. Eur Respir J 19: 626-631.

22. Report of the expert committee on the diagnosis and classification of diabetes mellitus, 1997 Diabetes Care 20: 1183-1197.

23. Haffner SM, Kennedy E, Gonzalez C, et al, 1996 A prospective analysis of the HOMA-IR model: the Mexico City Diabetes Study. Diabetes Care 19:11381141.

24. Bray G, 1998 Contemporary diagnosis and management of obesity. Handbooks and Healthcare Company, Pennsylvania.
25. Fernandez-Real JM, Vayreda M, Richart C, et al, 2001 Circulating Interleukin 6 Levels, Blood Pressure, and Insulin Sensitivity in Apparently Healthy Men and Women. J Clin Endocrinol Metab 86: 1154-1159.

26. Lemieux I, Pascot A, Prud'homme D, et al, 2001 Elevated $\mathrm{C}$-reactive protein: another component of the atherothrombotic profile of abdominal obesity. Arterioscler Thromb Vasc Biol 21: 961-967.

27. Forouhi NG, Sattar N, McKeigue PM, 2001 Relation of C-reactive protein to body fat distribution and features of the metabolic syndrome in Europeans and South Asians. Int J Obes Relat Metab Disord 25: $1327-$ 1331.

28. Danesh J, Collins R, Appleby P, Peto R, 1998 Association of fibrinogen, C-reactive protein, albumin, or leukocyte count with coronary heart disease: metaanalyses of prospective studies. JAMA 279: 1477-1482.

29. Ridker PM, 2000 Novel risk factors and markers for coronary disease. Adv Intern Med 45: 391-418.

30. Tracy RP, 1999 Inflammation markers and coronary heart disease. Curr Opin Lipidol 10: 435-441.

31. Rifai N, Ridker PM, 2001 Proposed cardiovascular risk assessment algorithm using high-sensitivity C-reactive protein and lipid screening. Clin Chem 47: 28-30.

32. Tracy RP, 1998 Inflammation in cardiovascular disease: cart, horse, or both? Circulation 97: 2000-2002.

33. Festa A, D'Agostino RJ, Howard G, et al, 2000 Chronic subclinical inflammation as part of the insulin resistance syndrome: the Insulin Resistance Atherosclerosis Study (IRAS). Circulation 102: 42-47.

34. Wajchenberg BL, 2000 Subcutaneous and visceral adipose tissue: their relation to metabolic syndrome. Endocr Rev 21: 697-738.

35. Arcaro G, Cretti A, Balzano S, et al, 2002 Insulin causes endothelial dysfunction in humans: sites and mechanisms. Circulation 105: 576-582.

36. Steppan CM, Bailey ST, Bhat S, et al, 2001 The hormone resistin links obesity to diabetes. Nature 409: 307312 .

37. Krieger-Brauer HI, Kather H, 1992 Human fat cells possess a plasma membrane-bound $\mathrm{H}_{2} \mathrm{O}_{2}$-generating system that is activated by insulin via a mechanism bypassing the receptor kinase. J Clin Invest 89: 1006-1013.

38. DeFronzo RA, Ferrannini E, 1991 Insulin resistance: a multifaceted syndrome responsible for NIDDM, obesity, hypertension and atherosclerotic cardiovascular disease. Diabetes Care 14: 173-194.

39. Katsuki A, SumidaY, Urakawa H, et al, 2004 Increased Oxidative Stress is Associated with Serum Levels of Triglyceride, Insulin Resistance, and Hyperinsulinemia in Japanese Metabolically Obese, Normal-Weight Men. Diabetes Care 27: 631-632. 